\title{
Stage III
}

National Cancer Institute

\section{Source}

National Cancer Institute. Stage III. NCI Thesaurus. Code C27970.

Locally advanced cancer that has spread to nearby organs but not to distant anatomic sites. 